\title{
Control of a multi-hospital outbreak of KPC-producing Klebsiella pneumoniae type 2 in France, September to October 2009
}

A Carbonne (anne.carbonne@sap.aphp.fr) ${ }^{1}$, J M Thiolet ${ }^{2}$, S Fournier ${ }^{3}$, N Fortineau ${ }^{4}$, N Kassis-Chikhani ${ }^{5}$, I Boytchev $^{4}$, M Aggoune ${ }^{1}$,

J C Séguier ${ }^{6}$, H Sénéchal7, M P Tavolacci ${ }^{8}$, B Coignard ${ }^{2}$, P Astagneau ${ }^{1,9}$, V Jarlier $^{3,9,10}$

1. Centre de coordination de la lutte contre les infections nosocomiales (CCLIN, Regional Coordinating Centre for Nosocomial Infection Control), Paris-Nord, France

2. Institut de Veille Sanitaire (InVS, French Institute for Public Health Surveillance), Saint-Maurice, France

3. Central infection control team, Assistance Publique - Hôpitaux de Paris, France

4. Assistance Publique-Hôpitaux de Paris, Centre Hospitalier Universitaire Bicêtre, Le Kremlin Bicêtre, France

5. Assistance Publique-Hôpitaux de Paris, Centre Hospitalier Universitaire Paul Brousse, Villejuif, France

6. Centre Hospitalier Poissy-St-Germain-en-Laye), Poissy and St-Germain-en-Laye, France

7. Centre de coordination de la lutte contre les infections nosocomiales (CCLIN, Regional Coordinating Centre for Nosocomial Infection Control) Ouest, Rennes, France

8. Centre Hospitalier Universitaire (CHU) Rouen, France

9. Université Pierre et Marie Curie, Paris, France

10. Microbiology-Infection control, Groupe Hospitalier Pitié-Salpêtrière, Paris, France

Citation style for this article:

Carbonne A, Thiolet JM, Fournier S, Fortineau N, Kassis-Chikhani N, Boytchev I, Aggoune M, Séguier JC, Sénéchal H, Tavolacci MP, Coignard B, Astagneau P, Jarlier V. Control of a multi-hospital outbreak of KPC-producing Klebsiella pneumoniae type 2 in France, September to October 2009 . Euro Surveill. 2010;15(48):pii=19734. Available online: http://www.eurosurveillance.org/ViewArticle.aspx?Articleld=19734

Article published on 2 December 2010

An outbreak of Klebsiella pneumoniae carbapenemase (KPC)-producing Klebsiella pneumoniae type 2 was detected in September 2009 in two hospitals in a suburb south of Paris, France. In total, 13 KPC-producing $K$. pneumoniae type 2 cases (four with infections and nine with digestive-tract colonisations) were identified, including a source case transferred from a Greek hospital. Of the 13 cases, seven were secondary cases associated with use of a contaminated duodenoscope used to examine the source case (attack rate: $41 \%$ ) and five were secondary cases associated with patient-topatient transmission in hospital. All isolated strains from the 13 patients: (i) exhibited resistance to all antibiotics except gentamicin and colistin, (ii) were more resistant to ertapenem (minimum inhibitory concentration (MIC) always greater than $4 \mathrm{mg} / \mathrm{L}$ ) than to imipenem (MIC: $1-8 \mathrm{mg} / \mathrm{L}$, depending on the isolate), (iii) carried the bla $a_{\mathrm{KPC}-2}$ and bla ${ }_{\mathrm{SHV}_{12}}$ genes and (iv) had an indistinguishable pulsed-field gel electrophoresis (PFGE) pattern. These cases occurred in three hospitals: some were transferred to four other hospitals. Extended infection control measures implemented in the seven hospitals included: (i) limiting transfer of cases and contact patients to other wards, (ii) cohorting separately cases and contact patients, (iii) reinforcing hand hygiene and contact precautions and (iv) systematic screening of contact patients. Overall, 341 contact patients were screened. A year after the outbreak, no additional case has been identified in these seven hospitals. This outbreak emphasises the importance of rapid identification and notification of emerging highly resistant $K$. pneumoniae strains in order to implement reinforced control measures.

\section{Introduction}

The emergence of Klebsiella pneumoniae carbapenemase (KPC)-producing Klebsiella pneumoniae type 2 (hereafter referred to as KPC-2 K. pneumoniae) has been reported worldwide and is becoming a major clinical and public health concern [1]. Such pathogens remain rare in France although a few outbreaks have been reported [2]. In this paper we describe a multi-hospital outbreak of KPC-2 K. pneumoniae, which occurred in a suburb south of Paris, France, in September and October 2009.

Alert of a healthcare-associated infection

A national healthcare-associated infection early warning and response system was set up in France in 2001, coordinated at national level by the French public health surveillance institute (Institut de Veille Sanitaire, InVS) [3]. Through this system, two university hospitals (Hospitals A and B) in a suburb of south of Paris each reported KPC-2 K. pneumoniae bacteraemia in one patient at the end of September 2009 to the Regional Coordinating Centre for Nosocomial Infection Control (Centre de coordination de la lutte contre les infections nosocomiales (CCLIN Paris-Nord)) in northern France and to the regional health authorities. The case in Hospital A was notified the day before the notification of the case in Hospital B. These hospitals belonged to the same institution, the Assistance Publique-Hôpitaux de Paris.

\section{Epidemiological investigations}

In response to the notifications from the two hospitals, local infection control teams carried out epidemiological investigations with the support of the regional 
Spatio-temporal description: multi-hospital outbreak of KPC-2 Klebsiella pneumoniae , France, September to October 2009 $(n=13)$

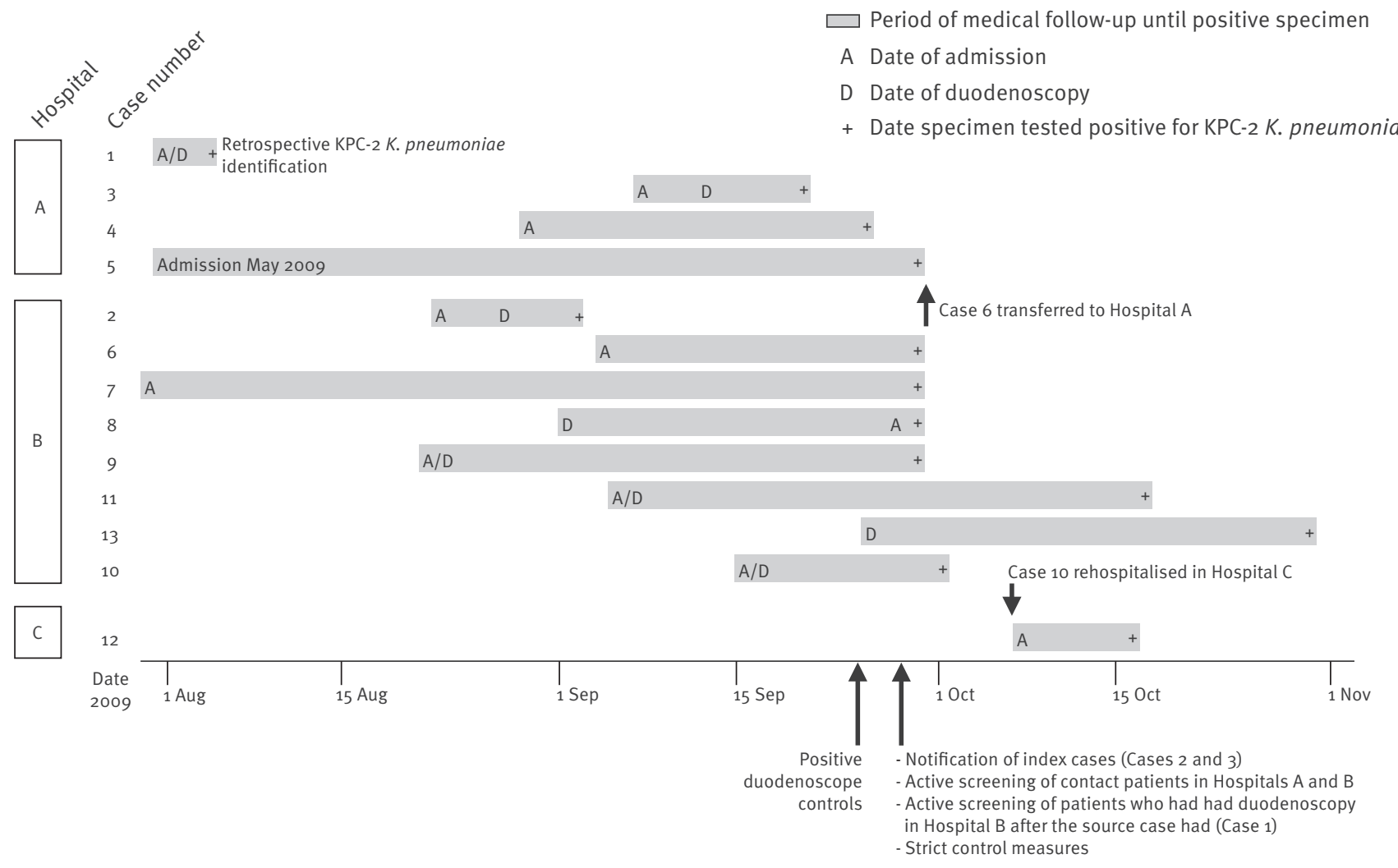

a Klebsiella pneumoniae carbapenemase (KPC)-producing Klebsiella pneumoniae type 2.

TABLE

Case description ${ }^{\mathrm{a}}$ : multi-hospital outbreak of KPC-2 Klebsiella pneumoniae ${ }^{\mathrm{b}}$, France, September to October 2009 (n=13)

\begin{tabular}{|c|c|c|c|c|c|c|}
\hline $\begin{array}{l}\text { Case } \\
\text { number }\end{array}$ & Hospital $^{c}$ & $\begin{array}{l}\text { Duodenoscopy in } \\
\text { Hospital B }\end{array}$ & $\begin{array}{l}\text { Type of specimen } \\
\text { tested }\end{array}$ & $\begin{array}{l}\text { Infection/ } \\
\text { colonisation }\end{array}$ & $\begin{array}{c}\text { Outcome as of } \\
1 \text { November } 2010\end{array}$ & Comment \\
\hline 1 & A & Yes & Rectal swab & Colonisation & Alive & $\begin{array}{c}\text { Source case } \\
\text { (transferred from Greece) }\end{array}$ \\
\hline 2 & B & Yes & Blood sample & $\begin{array}{c}\text { Infection } \\
\text { (bacteraemia) }\end{array}$ & $\begin{array}{l}\text { Death unrelated to } \\
\text { KPC-2 K. pneumoniae }\end{array}$ & Index case Hospital B \\
\hline 3 & A & Yes & Blood sample & $\begin{array}{c}\text { Infection } \\
\text { (bacteraemia) }\end{array}$ & $\begin{array}{l}\text { Death unrelated to } \\
\text { KPC-2 K. pneumoniae }\end{array}$ & Index case Hospital A \\
\hline 4 & A & No & Biliary fluid & $\begin{array}{c}\text { Infection } \\
\text { (biliary) }\end{array}$ & Alive & Contact of Case 3 \\
\hline 5 & A & No & Bronchial aspirate & $\begin{array}{l}\text { Infection } \\
\text { (pulmonary) }\end{array}$ & $\begin{array}{l}\text { Death unrelated to } \\
\text { KPC-2 K. pneumoniae }\end{array}$ & Contact of Case 3 \\
\hline 6 & B & No & Rectal swab & Colonisation & Alive & $\begin{array}{c}\text { Contact of Case } 2 \\
\text { Transferred to Hospital A }\end{array}$ \\
\hline 7 & $\mathrm{~B}$ & No & Rectal swab & Colonisation & Alive & Contact of Case 2 \\
\hline 8 & $B$ & Yes & Rectal swab & Colonisation & Alive & - \\
\hline 9 & B & Yes & Rectal swab & Colonisation & Alive & $\begin{array}{l}\text { Transferred to Hospital D then to } \\
\text { Hospital E }\end{array}$ \\
\hline 10 & B & Yes & Rectal swab & Colonisation & $\begin{array}{l}\text { Alive: urinary tract } \\
\text { colonisation in } 2010\end{array}$ & $\begin{array}{l}\text { Index case Hospital C } \\
\text { Returned home from Hospital B, } \\
\text { then re-hospitalised in Hospital C }\end{array}$ \\
\hline 11 & B & Yes & Rectal swab & Colonisation & $\begin{array}{l}\text { Death unrelated to } \\
\text { KPC-2 K. pneumoniae }\end{array}$ & $\begin{array}{l}\text { Underwent follow-up in Hospitals } \\
\text { F and G }\end{array}$ \\
\hline 12 & $\mathrm{C}$ & No & Rectal swab & Colonisation & Alive & Contact of Case 10 \\
\hline 13 & $\mathrm{~B}$ & Yes & Rectal swab & Colonisation & Alive & Underwent follow-up in Hospital G \\
\hline
\end{tabular}

a Reasons for hospitalisation included biliary or gall bladder lithiasis, gastrointestinal carcinoma, gastrointestinal haemorrhage, hepatic transplantation and peritonitis.

${ }^{\mathrm{b}}$ Klebsiella pneumoniae carbapenemase (KPC)-producing Klebsiella pneumoniae type 2.

${ }^{\mathrm{C}}$ Hospital where KPC-2 K. pneumoniae was diagnosed. 
infection control coordination centre and of the central infection control team of the Assistance PubliqueHôpitaux de Paris.

A case was defined as a person from whom KPC-2 $K$. pneumoniae was identified microbiologically in rectal swabs taken as part of systematic screening or in clinical specimens. A contact patient was defined as a person who shared the same unit and the same healthcare workers as a case. All contact patients in hospital wards were listed and screening was proposed to them.

\section{Outbreak description}

Source case

Preliminary results of the epidemiological investigation at the end of September 2009 indicated that the first two cases notified from Hospitals $A$ and $B$ had undergone duodenoscopy in Hospital B at the end of August and in early September 2009 with the same duodenoscope. Following notification of these two cases, retrospective analysis of the charts of all patients who had undergone duodenoscopy since March 2009 (the date of the last maintenance by the manufacturer) in Hospital $B$ with the same duodenoscope used for the two cases pointed to a likely source case - a patient examined by duodenoscopy at the end of July 2009 in Hospital B. The endoscopy was carried out in Hospital $B$, but the patient stayed in Hospital $A$, after being transferred from a hospital in Greece, where KPC-2 K. pneumoniae is endemic [4]. Screening for all Enterobacteriaceae resistant to third-generation cephalosporins, in a rectal swab on admission - routinely performed in Hospital A since a previous outbreak [2] - was negative for this likely source case, but a subsequent swab was positive (at the start of August 2009). The bacterial strain had first been considered as susceptible to carbapenems (with an imipenem minimum inhibitory concentration (MIC) of $1.5 \mathrm{mg} / \mathrm{L}$ ), but during the outbreak investigation in September 2009, the laboratory of Hospital A detected the $b a_{\mathrm{KPC}-2}$ gene in this isolate. It was therefore retrospectively considered as the first isolate of KPC-2 K. pneumoniae in Hospital A, and the case from whom it was isolated as the source case of the outbreak.

\section{Secondary cases}

There were two further cases of KPC-2 K. pneumoniae infection (biliary and pulmonary) in Hospital A at the end of September 2009 (Cases 4 and 5); the infection was acquired by patient-to-patient transmission in the same ward. These patients had not undergone endoscopy but their stay overlapped with the stay in Hospital A of the first case notified by this hospital (Case 3) [5] (Figure).

Active screening of contact patients was then conducted in Hospitals A and B: all isolated extended-spectrum beta-lactamase (ESBL)-producing Enterobacteriaceae were screened for susceptibility to carbapenems (imipenem and ertapenem) and the MICs were determined.
No other cases were identified among 87 contact patients in Hospital A, but two new cases (Cases 6 and 7) were identified among 208 contact patients in Hospital B. A total of 295 of 342 contact patients (86\%) were screened in these two hospitals.

Of the 17 patients who had undergone endoscopy in Hospital B since March 2009 with the same duodenoscope as that used for the source case, two were the notified index cases with bacteraemia, five had KPC-2 K. pneumoniae-positive rectal swabs, nine were negative after three screenings over the course of the two-week investigation and one died before the investigation started. The carrier status of one of these five KPC-2 K. pneumoniae-positive patients (Case 10) was determined at the start of October 2009, but the patient was discharged the same day, to go home. The patient was subsequently readmitted (in early October) to an intensive care unit in a third hospital (Hospital C), without information about their KPC-2 K. pneumoniae status. After the infection control practitioner of Hospital B had been informed by physicians about the patient's readmission to Hospital C, they informed their counterpart in Hospital $\mathrm{C}$, so that screening and control measures could be implemented. As a result of screening of 25 contact patients in Hospital C, one secondary case was identified (Case 12).

Four cases were transferred to or had medical followup in four other hospitals (Hospitals D to $G$ ): one was in the same region as Hospitals $A$ and $B$ and three were in neighbouring regions. The cases' KPC-2 K. pneumoniae status was known at the time of transfer or follow-up. In Hospitals D and E, there were no contact patients; in Hospital F, three contact patients were screened and in Hospital G, 18 were screened (at least one rectal swab from each contact patient was obtained and screened). No further cases were identified in Hospitals D to G.

By the end of October 2009, 13 KPC-2 K. pneumoniae cases (four with infections and nine with digestivetract colonisations) had been identified in Hospitals A to C (Table), comprising one source case, seven secondary cases among the 17 patients who underwent endoscopy with the same duodenoscope (attack rate: $41 \%$ ) and five secondary cases among the 341 contact patients in Hospitals A to $G$ (attack rate: $1.5 \%$ ). There were no deaths related to $\mathrm{KPC}-2 \mathrm{~K}$. pneumoniae infection. As of 1 November 2010, no new case involving the same strain has been identified in these seven hospitals.

\section{Microbiological investigations}

Carbapenem resistance of the isolated bacterial strains was initially detected by routine methods [6]. The MIC of imipenem and ertapenem was determined by Etest (Bio-Rad). The presence of the $b l a_{\mathrm{KPC}-2}$ gene and $b l a_{\mathrm{SHV}_{12}}$ gene was identified by polymerase chain reaction $(P C R)$ and DNA sequencing. 
In Hospital A, all ESBL-producing $K$. pneumoniae strains that had been isolated in the six months before the outbreak were re-investigated, to screen for carbapenemase production using the modified Hodge test and ethylenediaminetetraacetic acid (EDTA)-disc synergy [7] and PCR.

Rectal swabs or clinical specimens were screened for Enterobacteriaceae resistant to third-generation cephalosporins by plating on Drigalski agar containing $0.5 \mathrm{mg} / \mathrm{L}$ cefotaxime and MacConkey agar containing $2 \mathrm{mg} / \mathrm{L}$ ceftazidime (AES Laboratoire) [5], a medium commonly used in France for ESBL-producing strains. Indeed strains resistant to carbapenems are also resistant to third-generation cephalosporins. All bacteria that grew were identified at the species level and tested for susceptibility to various drugs, including carbapenems. The laboratory of Hospital B performed pulsed-field gel electrophoresis (PFGE) of genomic DNA of the isolated bacteria using $X b a 1$ restriction enzyme.

Duodenoscope disinfection controls were performed according to the national recommendations of the French Ministry of Health published in 2007 [8]. After disinfection, $100 \mathrm{ml}$ of sterile wash solution were aseptically injected in all channels of the endoscope. The wash solution was collected at the other end of the duodenoscope and cultured on standard culture medium at various temperatures. If the cultures were positive, each channel was tested individually. Bacterial colonies were counted and identified according to standard methods [6].

At the end of September 2009, despite disinfection of the endoscope, two microbiological controls of the duodenoscope used by the source and some subsequent cases revealed the presence of faecal flora (Enterobacteriaceae and Enterococcus), including KPC-2 K. pneumoniae strains ( $10^{3}$ colony-forming units (CFU)/ $\mathrm{ml}$ ) with an indistinguishable PFGE pattern. No other multidrug-resistant bacteria were found.

As already described in reports focusing on microbiological aspects of this outbreak $[5,9]$, the KPC-2 $K$. pneumoniae strains isolated from all 13 cases and from the duodenoscope showed resistance or intermediate susceptibility to all antibiotics except gentamicin and colistin. The MIC for imipenem varied between $1.5 \mathrm{mg} / \mathrm{L}$ and $8 \mathrm{mg} / \mathrm{L}$, depending on the isolate. However, the MIC for ertapenem was always greater than $4 \mathrm{mg} / \mathrm{L}$. PCR analysis of the outbreak strain identified the bla $a_{\mathrm{KPC}-2}$ and the $b a_{\mathrm{SHV}} 12$ genes encoding respectively a carbapenemase and an ESBL [5]. Two other betalactamase genes were identified: bla $a_{\mathrm{TEM}-1}$ and $b / a_{\mathrm{OXA}-9^{\circ}}$ Multilocus sequence typing, performed as previously described [10], showed that all strains belonged to sequence type (ST) 258 , [11,12]. The PFGE patterns of all the isolates were indistinguishable.

\section{Infection control measures}

\section{Evaluation of duodenoscope disinfection} practices and maintenance

The duodenoscope in question had been acquired by Hospital B in 2003 and was therefore rather old in 2009, but had been regularly maintained. A new, automated cleaning device had been in use for a year; peracetic acid had been used instead of glutaraldehyde for disinfection. The cleaning and disinfection processes were consistent with guidelines [13] but the drying process was not optimal.

The duodenoscope was sent to the manufacturer during the outbreak investigation for maintenance, cleaning and desinfection. No signs of damage were identified. Disinfection procedures were reviewed and disinfection practices were observed by the local infection control team of Hospital B with the support of the regional infection control coordination centre and of the central infection control team of the Assistance Publique-Hôpitaux de Paris. The disinfection procedures were revised, to include a systematic and complete drying step after each disinfection cycle. After the outbreak, microbiological controls of the duodenoscope were performed more frequently (monthly). Since January 2010, controls have been carried out every three months (before the outbreak, they were performed every six months).

\section{Hospital infection control procedures}

Extended infection control measures were implemented in each of the seven hospitals involved by local infection control teams with the support of hospital administrators, coordinated by the regional infection control coordination centre and, in Hospitals $A$ and $B$, also by the central infection control team of the Assistance Publique-Hôpitaux de Paris. The objective of these measures was to prevent future patient-topatient transmission and included: (i) limiting transfer of cases and contact patients to other wards until the case was discharged from hospital, (ii) cohorting cases and contact patients in separate units with different healthcare workers, until discharge [14], (iii) flagging the presence of cases by displaying a specific poster or logo on the doors of cases' rooms and in the part of the ward where cases were cohorted, (iv) reinforcing hand hygiene (more and better use of hydroalcoholic solutions) and contact precautions, and (v) systematic screening of contact patients.

In Hospitals D and E, strengthened control measures were immediately implemented at the time of admission of cases, to ensure that no patients came into contact with a case.

\section{Discussion}

Carbapenemase-producing $K$. pneumoniae have increasingly been isolated from patients in healthcare settings worldwide [1] and are already endemic in some countries. In Europe, Greece has the highest prevalence of carbapenem-resistant $K$. pneumoniae strains; 
other countries such as Israel and the east coast of the United States also have a high prevalence $\left[\begin{array}{ll}1 & 15,16] \text {. }\end{array}\right.$ In France, a few KPC K pneumoniae cases have been reported, mostly from patients transferred from hospitals in the three countries mentioned $[1,17,18]$.

Hospital A receives numerous patients from hospitals in Greece and the Middle East and has already described an outbreak of Verona integron-encoded metallo-betalactamase (VIM)-producing $K$. pneumoniae and its control [14]. Stringent control measures - such as those described during the outbreak described in this report - are implemented on the admission of such patients, to prevent patient-to-patient transmission. In order to assist hospitals in the implementation of such control measures, national guidelines on screening patients transferred from abroad have been recently published in France [19].

The outbreak described in this report highlights the risk of transmitting multidrug-resistant bacteria through endoscopy, particularly through invasive procedures such as duodenoscopy, and by patient-topatient transmission in hospital. Our analysis showed that seven of the 17 patients who underwent endoscopy with the same duodenoscope used for the source case were contaminated with the outbreak strain over a period of two months. Together with the indistinguishable PFGE pattern, this strongly suggests that this duodenoscope represented a persistent source of contamination. A review showed that endoscopy-associated outbreaks are related to inadequate endoscope cleaning, although the risk of exogenous infection from endoscopes that have been appropriately reprocessed is very low [20]. This review reinforces the need for: (i) adequate drying after each reprocessing cycle, (ii) reprocessing endoscopes after a period of non-use, (iii) microbiological surveillance and (iv) coordinated handling of post-contamination responses.

The outbreak presented here shows that is possible to limit cross-transmission of multidrug-resistant bacteria by healthcare workers in a multi-hospital setting by implementing systematic investigation (including screening of contact patients) and extended control measures (including cohorting separately case and contact patients), as recommended by the French health authorities for controlling the spread of multidrug-resistant bacteria $[19,21]$. However, several weaknesses of the infection control organisation during this outbreak should be pointed out: (i) the source case was only identified retrospectively, due to the difficulty of identifying carbapenemase production in bacterial strains with a low level of resistance to some carbapenems; (ii) there was a delay in issuing an alert warning after the identification of the first two index cases in Hospitals A and B, which led to a high number of contact patients; (iii) one case from Hospital $B$ was transferred to another hospital without information about the previous hospital stay of this patient or the patient's KPC-2 K. pneumoniae carrier status. The lessons learnt from this outbreak may help to improve the efficiency of control in future outbreaks and to prevent further outbreaks.

Reactivity and preparedness of local and regional personnel (e.g. microbiologists, healthcare workers and infection control teams) are likely to be crucial in controlling emerging multidrug-resistant pathogens [22]. In addition, clear and comprehensive recommendations for microbiological laboratories will facilitate the early detection of carbapenemase-producing organisms [1]. This outbreak also demonstrates the usefulness of a coordinated healthcare-associated infection early warning and response system in rapidly implementing a multi-hospital investigation, providing assistance to hospitals for screening and infection control measures, and controlling the spread of an emerging pathogen.

\section{Acknowledgements}

We would like to acknowledge the healthcare workers who contributed to the investigation and the control of this outbreak. Special thanks are due to M. Godard, infection control nurse, and G. Cuzon, who performed the PFGE comparison.

\section{References}

1. Nordmann P, Cuzon G, Naas T. The real threat of Klebsiella pneumoniae carbapenemase-producing bacteria. Lancet Infect Dis. 2009;9(4):228-36.

2. Kassis-Chikhani N, Decré D, Gautier V, Burghoffer B, Saliba F, Mathieu D, et al. First outbreak of multidrug-resistant Klebsiella pneumoniae carrying blaVIM-1 and blaSHV-5 in a French university hospital. .J Antimicrob Chemother. 2006;57(1):142-5.

3. Desenclos JC, RAISIN Working Group. RAISIN - a national programme for early warning, investigation and surveillance of healthcare-associated infection in France. Euro Surveill. 2009;14(4). pii: 19408. Available from: http://www. eurosurveillance.org/ViewArticle.aspx?Articleld=19408

4. Giakoupi P, Maltezou H, Polemis M, Pappa O, Saroglou G, Vatopoulos A, et al .KPC-2-producing Klebsiella pneumoniae infections in Greek hospitals are mainly due to a hyperepidemic clone. Euro Surveill. 2009 May 28;14(21). pii: 19218. Available from: http://www.eurosurveillance.org/ ViewArticle.aspx?Articleld $=19218$

5. Kassis-Chikhani N, Decré D, Ichai P, Sengelin C, Geneste $D$, Mihaila L, et al. Outbreak of Klebsiella pneumoniae producing KPC-2 and SHV-12 in a French hospital. J Antimicrob Chemother. 2010 Jul;65(7):1539-40.

6. Société Française de Microbiologie. Recommendation 2007 of the Committee of the Antibiogram of the French Society of Microbiology (CA-SFM). Available from: http://www.sfm.asso. $\mathrm{fr} /$ doc/download.php?doc=DiU8C\&fic=casfm_2010.pdf

7. Tsakris A, Kristo I, Poulou A, Markou F, Ikonomidis A, Pournaras S. First occurrence of KPC-2-possessing Klebsiella pneumoniae in a Greek hospital and recommendation for detection with boronic acid disc tests. J Antimicrob Chemother. 2008;62(6):1257-60.

8. Ministère de la Santé et de la Solidarité, Direction Générale de la Santé, Direction de l'Hospitalisation et de l'Offre de Soins, Comité Technique des Infections Nosocomiales et des infections liées aux Soins. [Elements of quality assurance in microbiological controls and traceability in endoscopy]. 2007. French. Available from: http://www.sante-sports.gouv.fr/IMG/ pdf/microbio_endoscopes-2.pdf

9. Naas T, Cuzon G, Babics A, Fortineau N, Boytchev I, Gayral $F$, et al. Endoscopy-associated transmission of carbapenemresistant Klebsiella pneumoniae producing KPC-2 betalactamase. J Antimicrob Chemother. 2010;65(6):1305-6.

10. Diancourt L, Passet V, Verhoef J, Grimont PA, Brisse S. Multilocus sequence typing of Klebsiella pneumoniae nosocomial isolates. J Clin Microbiol. 2005;43(8):4178-82. 
11. Kitchel B, Rasheed JK, Patel JB, Srinivasan A, Navon-Venezia S, Carmeli Y, et al. Molecular epidemiology of KPC-producing Klebsiella pneumoniae isolates in the United States: clonal expansion of multilocus sequence type 258. Antimicrob Agents Chemother. 2009;53(8):3365-70.

12. Bogaerts P, Montesinos I, Rodriguez-Villalobos H, Blairon L, Deplano A, Glupczynski Y. Emergence of clonally related Klebsiella pneumoniae isolates of sequence type 258 producing KPC-2 carbapenemase in Belgium. J Antimicrob Chemother. 2010;65(2):361-2.

13. Ministère de la santé et de la protection sociale, Comité Technique des Infections Nosocomiales. [Guidelines for automatic disinfection of endoscopes]. 2003. French. Available from: http://www.sante-jeunesse-sports.gouv.fr/IMG/pdf/ Guide_pour_l_utilisation_des_laveurs_desinfecteurs_d_ endoscopes.pdf

14. Kassis-Chikhani N, Saliba F, Carbonne A, Neuville S, Decre $D$, Sengelin C, et al. Extended measures for controlling an outbreak of VIM-1 producing imipenem-resistant Klebsiella pneumoniae in a liver transplant centre in France, 2003-2004. Euro Surveill. 2010;15(46):pii=19713. Available online: http:// www.eurosurveillance.org/ViewArticle.aspx?Articleld=19713

15. Pitout JD, Laupland KB. Extended-spectrum beta-lactamaseproducing Enterobacteriaceae: an emerging public-health concern. Lancet Infect Dis. 2008;8(3):159-66.

16. European Antimicrobial Resistance Surveillance System (EARSS). EARSS annual report 2008. Available from: http:// ecdc.europa.eu/en/activities/surveillance/EARS-Net/ Documents/2008_EARSS_Annual_Report.pdf

17. Barbier F, Ruppé E, Giakkoupi P, Wildenberg L, Lucet J, Vatopoulos A, et al. Genesis of a KPC-producing Klebsiella pneumoniae after in vivo transfer from an imported Greek strain. Euro Surveill. 2010;15(1). pii: 19457. Available from: http://www.eurosurveillance.org/ViewArticle. aspx?Articleld $=19457$

18. Institut de Veille Sanitaire. Review of notifications to French public health surveillance institute (Institut de Veille Sanitaire, InVS) of infections or colonisations with carbapenemaseproducing Enterobacteriaceae in France. 2004-2010 Available since October 2010 from: http://www.invs.sante.fr/ surveillance/enterobacteries/bilan.htm

19. Haut Conseil de la Santé Publique. Commission spécialisée sécurité des patients: infections nosocomiales et autres évènements indésirables liés aux soins et aux pratiques. [Screening of faecal carriage and transmission control of multidrug resistant bacteria in patients hospitalised in French hospitals through transfers from another country]. Paris: May 2010. French. Available from: http://www.hcsp.fr/docspdf/ avisrapports/hcspr20100518_bmrimportees.pdf

20. Seoane-Vazquez E, Rodriguez-Monguio R. Endoscopyrelated infection: relic of the past? Curr Opin Infect Dis. 2008;21(4):362-6.

21. Haut Conseil de la Santé Publique. Commission spécialisée Sécurité des Patients : infections nosocomiales et autres événements indésirables liés aux soins et aux pratiques. [Report about control measures for emergence and diffusion of glycopeptide resistant Enterococci in French healthcare facilities]. Paris: March 2010. French. Available from: http:// www.hcsp.fr/explore.cgi/hcspr20090219_ERG.pdf

22. Carmeli Y, Akova M, Cornaglia G, Daikos GL, Garau J, Harbarth $\mathrm{S}$, et al. Controlling the spread of carbapenemase-producing Gram-negatives: therapeutic approach and infection control. Clin Microbiol Infect. 2010;16(2):102-11. 